\title{
Comparison of FACTS Devices for Power System Stability Enhancement
}

\author{
D. Murali \\ Research Scholar in EEE Dept., \\ Government College of Engineering, Government College of Engineering, \\ Bargur-635 104, Tamilnadu, India.
}

\author{
N. Reka \\ Lecturer / EEE, \\ Paavai College of Engineering, \\ Namakkal-637 018, Tamilnadu, \\ India.
}

\begin{abstract}
The development of the modern power system has led to an increasing complexity in the study of power systems, and also presents new challenges to power system stability, and in particular, to the aspects of transient stability and small-signal stability. Transient stability control plays a significant role in ensuring the stable operation of power systems in the event of large disturbances and faults, and is thus a significant area of research. This paper investigates the improvement of transient stability of a two-area power system, using UPFC (Unified Power Flow Controller) which is an effective FACTS (Flexible AC Transmission System) device capable of controlling the active and reactive power flows in a transmission line by controlling appropriately its series and shunt parameters. Simulations are carried out in Matlab/Simulink environment for the two-area power system model with UPFC to analyze the effects of UPFC on transient stability performance of the system. The performance of UPFC is compared with other FACTS devices such as Static Synchronous Series Compensator (SSSC), Thyristor Controlled Series Capacitor (TCSC), and Static Var Compensator (SVC) respectively. The simulation results demonstrate the effectiveness and robustness of the proposed UPFC on transient stability improvement of the system.
\end{abstract}

\section{Keywords}

FACTS, Matlab/Simulink, SSSC, SVC, TCSC, Transient stability, Two-area power system, UPFC.

\section{INTRODUCTION}

Modern power system is a complex network comprising of numerous generators, transmission lines, variety of loads and transformers. As a consequence of increasing power demand, some transmission lines are more loaded than was planned when they were built. With the increased loading of long transmission lines, the problem of transient stability after a major fault can become a transmission limiting factor [1]. Now power engineers are much more concerned about transient stability problem due to blackout in northeast United States, Scandinavia, England and Italy. Transient stability refers to the capability of a system to maintain synchronous operation in the event of large disturbances such as multi-phase short-circuit faults or switching of lines [2]. The resulting system response involves large excursions of generator rotor angles and is influenced by the nonlinear power angle relationship. Stability depends upon both the initial operating conditions of the system and the severity of the disturbance. Recent development of power electronics introduces the use of flexible ac transmission system (FACTS) controllers in power systems. FACTS controllers are capable of controlling the network condition in a very fast manner and this feature of FACTS can be exploited to improve the voltage stability, and steady state and transient stabilities of a complex power system [3]-[8]. This allows increased utilization of existing network closer to its thermal loading capacity, and thus avoiding the need to construct new transmission lines.

Static VAR Compensator (SVC) is a first generation FACTS device that can control voltage at the required bus thereby improving the voltage profile of the system. The primary task of an SVC is to maintain the voltage at a particular bus by means of reactive power compensation (obtained by varying the firing angle of the thyristors) [9]. SVCs have been used for high performance steady state and transient voltage control compared with classical shunt compensation. SVCs are also used to dampen power swings, improve transient stability, and reduce system losses by optimized reactive power control [10]-[11].

Thyristor Controlled Series Capacitor (TCSC) is one of the important members of FACTS family that is increasingly applied with long transmission lines by the utilities in modern power systems. It can have various roles in the operation and control of power systems, such as scheduling power flow; decreasing unsymmetrical components; reducing net loss; providing voltage support; limiting short-circuit currents; mitigating subsynchronous resonance (SSR); damping the power oscillation; and enhancing transient stability [12]-[14].

A Static Synchronous Series Compensator (SSSC) is a member of FACTS family which is connected in series with a power system. It consists of a solid state voltage source converter which generates a controllable alternating current voltage at fundamental frequency. When the injected voltage is kept in quadrature with the line current, it can emulate as inductive or capacitive reactance so as to influence the power flow through the transmission line [15]. While the primary purpose of a SSSC is to control power flow in steady state, it can also improve transient stability of a power system.

Among the available FACTS devices, the Unified Power Flow Controller (UPFC) is the most versatile one that can be used to improve steady state stability, dynamic stability and transient stability [16]. The UPFC can independently control many parameters since it is the combination of Static Synchronous Compensator (STATCOM) and SSSC. These 
devices offer an alternative mean to mitigate power system oscillations. It has been reported in many papers that UPFC can improve stability of single machine infinite bus (SMIB) system and multimachine system [17]-[18]. The inter-area power system has special characteristic of stability behaviour [19]. This paper investigates the improvement of transient stability of a two-area power system with a UPFC. A Matlab/Simulink model is developed for a two-area power system with a UPFC. The performance of UPFC is compared with other FACTS devices such as SVC, TCSC, and SSSC respectively. From the simulation results, it is inferred that UPFC is an effective FACTS device for transient stability improvement.

\section{FACTS CONTROLLERS}

FACTS controllers may be based on thyristor devices with no gate turn-off or power devices with gate turn-off capability. FACTS controllers are used for the dynamic control of voltage, impedance and phase angle of high voltage AC transmission lines. The basic principles of the following FACTS controllers, which are used in the two-area power system under study, are discussed briefly.

\subsection{Static Var Compensator (SVC)}

Static var systems are applied by utilities in transmission applications for several purposes. The primary purpose is usually for rapid control of voltage at weak points in a network. Installations may be at the midpoint of transmission interconnections or at the line ends. Static Var Compensators are shunt connected static generators / absorbers whose outputs are varied so as to control voltage of the electric power systems. In its simple form, SVC is connected as Fixed Capacitor-Thyristor Controlled Reactor (FC-TCR) configuration as shown in Fig. 1. The SVC is connected to a coupling transformer that is connected directly to the ac bus whose voltage is to be regulated. The effective reactance of the FC-TCR is varied by firing angle control of the antiparallel thyristors. The firing angle can be controlled through a PI (Proportional + Integral) controller in such a way that the voltage of the bus, where the SVC is connected, is maintained at the reference value.

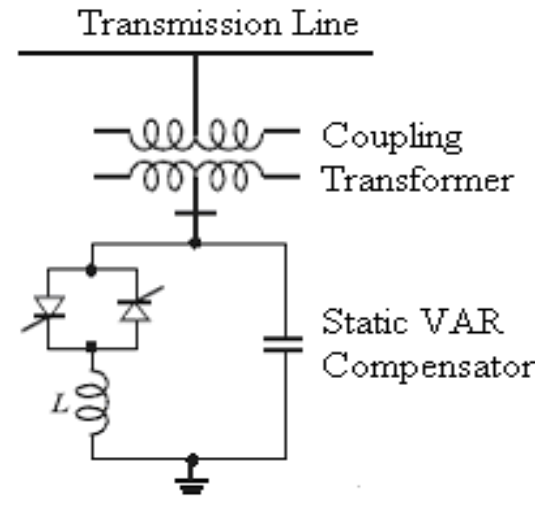

Fig. 1 Configuration of SVC

\subsection{Thyristor Controlled Series Capacitor (TCSC)}

TCSC is one of the most important and best known FACTS devices, which has been in use for many years to increase the power transfer as well as to enhance system stability. The main circuit of a TCSC is shown in Fig. 2. The TCSC consists of three main components: capacitor bank $\mathrm{C}$, bypass inductor $\mathrm{L}$ and bidirectional thyristors SCR1 and SCR2. The firing angles of the thyristors are controlled to adjust the TCSC reactance in accordance with a system control algorithm, normally in response to some system parameter variations. According to the variation of the thyristor firing angle or conduction angle, this process can be modeled as a fast switch between corresponding reactances offered to the power system.

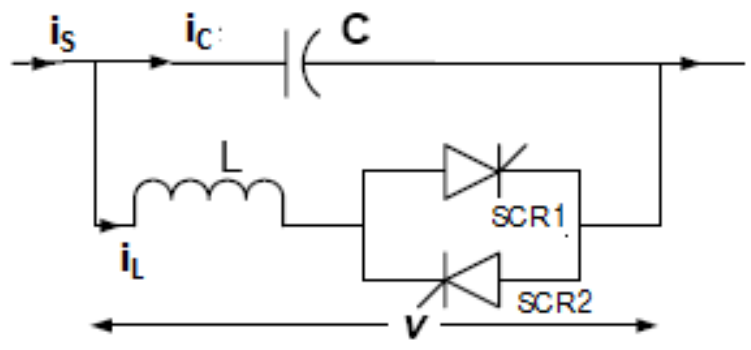

Fig. 2 Configuration of a TCSC

When the thyristors are fired, the TCSC can be mathematically described as:

$$
i_{c}=C \frac{d v}{d t} ; \quad v=L \frac{d i_{L}}{d t}
$$

where ' $v$ ' is the instantaneous voltage across the TCSC. The instantaneous current of the controlled transmission line is the sum of the instantaneous values of the currents in the capacitor banks and inductor respectively. Assuming that the total current passing through the TCSC is sinusoidal; the equivalent reactance at the fundamental frequency can be represented as a variable reactance $X_{T C S C}$. The TCSC can be controlled to work either in the capacitive or in the inductive zones avoiding steady state resonance. There exists a steady-state relationship between the firing angle $\alpha$ and the reactance $X_{T C S C}$. This relationship can be described by the following equation [20]:

$$
\begin{aligned}
& X_{\operatorname{TCSC}}(\alpha)=X_{c}-\frac{X_{c}^{2}}{\left(X_{c}-X_{p)}\right.} \frac{(\sigma+\sin \sigma)}{\pi}+ \\
& \frac{4 X_{c}^{2}}{\left(X_{c}-X_{p}\right)} \frac{\cos ^{2}(\sigma / 2)}{\left(k^{2}-1\right)} \frac{(k \tan (k \sigma / 2)-\tan (\sigma / 2))}{\pi}
\end{aligned}
$$

where, $X_{c}=$ Nominal reactance of the fixed capacitor C.

$$
\begin{gathered}
X_{p}=\text { Inductive reactance of inductor } \mathrm{L} \text { connected in parallel } \\
\text { with C. }
\end{gathered}
$$

$\sigma=2(\pi-\alpha)=$ Conduction angle of TCSC controller. 
$k=\sqrt{\frac{X_{c}}{X_{p}}}=$ Compensation ratio.

\subsection{Static Synchronous Series Compensator (SSSC)}

The SSSC is one of the most recent FACTS devices for power transmission series compensation. It can be considered as a synchronous voltage source as it can inject an almost sinusoidal voltage of variable and controllable amplitude and phase angle, in series with a transmission line. The injected voltage is almost in quadrature with the line current. A small part of the injected voltage that is in phase with the line current provides the losses in the inverter. Most of the injected voltage, which is in quadrature with the line current, provides the effect of inserting an inductive or capacitive reactance in series with the transmission line. The variable reactance influences the electric power flow in the transmission line. The basic configuration of a SSSC is shown in Fig. 3.

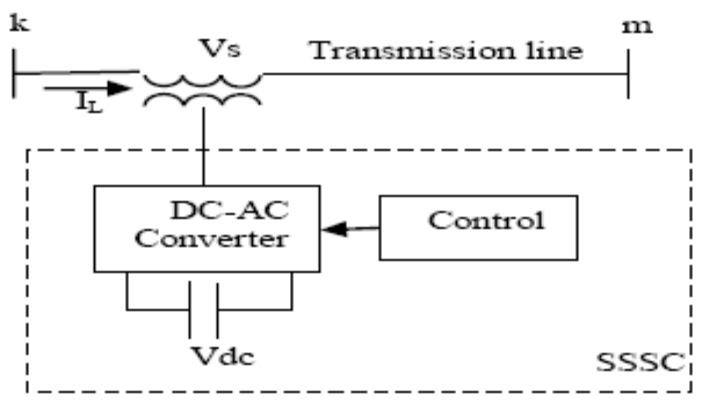

Fig. 3 Simplified diagram of a SSSC

\subsection{Unified Power Flow Controller (UPFC)}

Among the available FACTS devices, the Unified Power Flow Controller (UPFC) is the most versatile one that can be used to enhance steady state stability, dynamic stability and transient stability. The basic configuration of a UPFC is shown in Fig. 4. The UPFC is capable of both supplying and absorbing real and reactive power and it consists of two ac/dc converters. One of the two converters is connected in series with the transmission line through a series transformer and the other in parallel with the line through a shunt transformer. The dc side of the two converters is connected through a common capacitor, which provides dc voltage for the converter operation. The power balance between the series and shunt converters is a prerequisite to maintain a constant voltage across the dc capacitor. As the series branch of the UPFC injects a voltage of variable magnitude and phase angle, it can exchange real power with the transmission line and thus improves the power flow capability of the line as well as its transient stability limit. The shunt converter exchanges a current of controllable magnitude and power factor angle with the power system. It is normally controlled to balance the real power absorbed from or injected into the power system by the series converter plus the losses by regulating the dc bus voltage at a desired value.

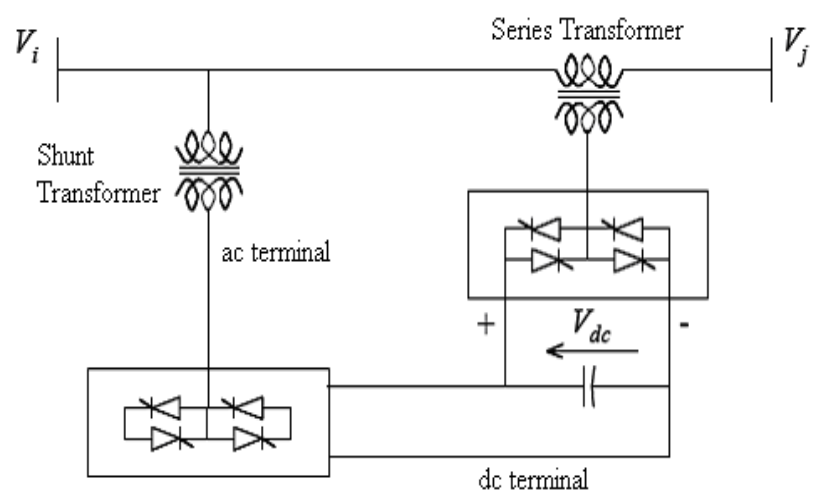

Fig. 4 Configuration of UPFC

\section{TWO AREA POWER SYSTEM MODEL}

Consider a two-area power system (Area-1 \& Area-2) with series and shunt FACTS devices, connected by a single circuit long transmission line as shown in Fig. 5 and Fig. 6. Here, the series FACTS devices such as UPFC (combination of STATCOM and SSSC), SSSC, and TCSC are equipped between bus- 2 and bus- 3 and the shunt FACTS device such as SVC is equipped at bus-2. The direction of real power flow is from Area-1 to Area-2. In the two-area power system model, the Area-1 consists of Generator 1 (G1) and Generator $2(\mathrm{G} 2)$ and the Area-2 consists of Generator 3 (G3) and Generator $4(\mathrm{G} 4)$. The system data are given in [21].

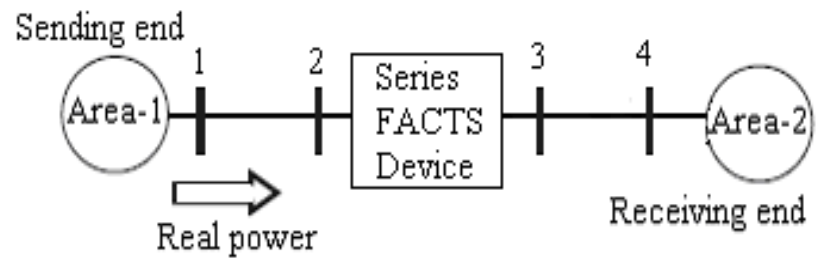

Fig. 5 Two-area power system with series FACTS device

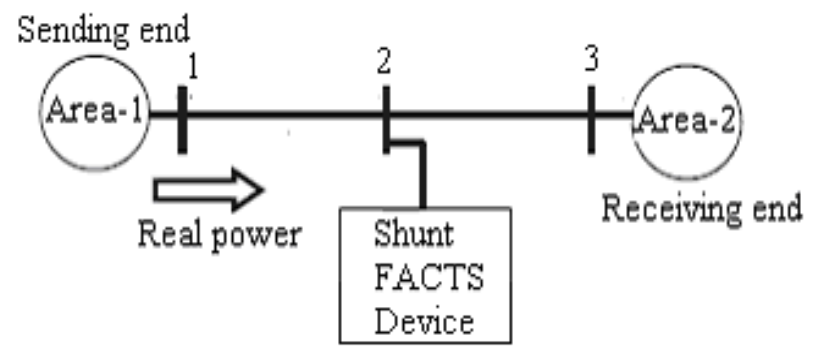

Fig. 6 Two-area power system with shunt FACTS device

\section{SIMULATION RESULTS AND DISCUSSION}

\subsection{Two-area Power System with UPFC}

The two-area system shown in Fig. 5 is considered in this study. The system has a UPFC installed between bus- 2 and bus- 3 . It is considered that a 3-phase symmetrical short-circuit fault of 300 milli-seconds duration occurs at bus-3. The system is simulated in Matlab/Simulink environment and the corresponding graphs are shown in Fig. 7 and Fig. 8. From the Fig. 7, it is inferred that 
without a UPFC, the oscillations in generator rotor angle of Area1 (Generator 1 and Generator 2) and Area-2 (Generator 3 and Generator 4) increase and the settling time for the oscillations is found to be high. However, from the Fig. 8, it can be seen that with a UPFC, the oscillations in generator rotor angle of Area-1 and Area-2 decrease and the settling time for the oscillations is found to be slightly low. Hence, the transient stability of the twoarea power system is improved with UPFC.

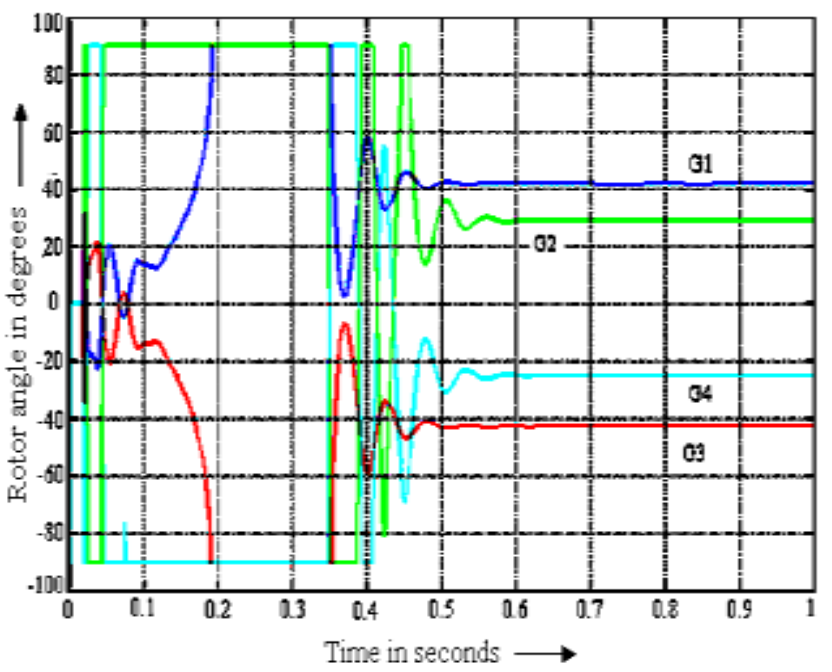

Fig. 7 Variation of generator rotor angle of the two-area power system without UPFC

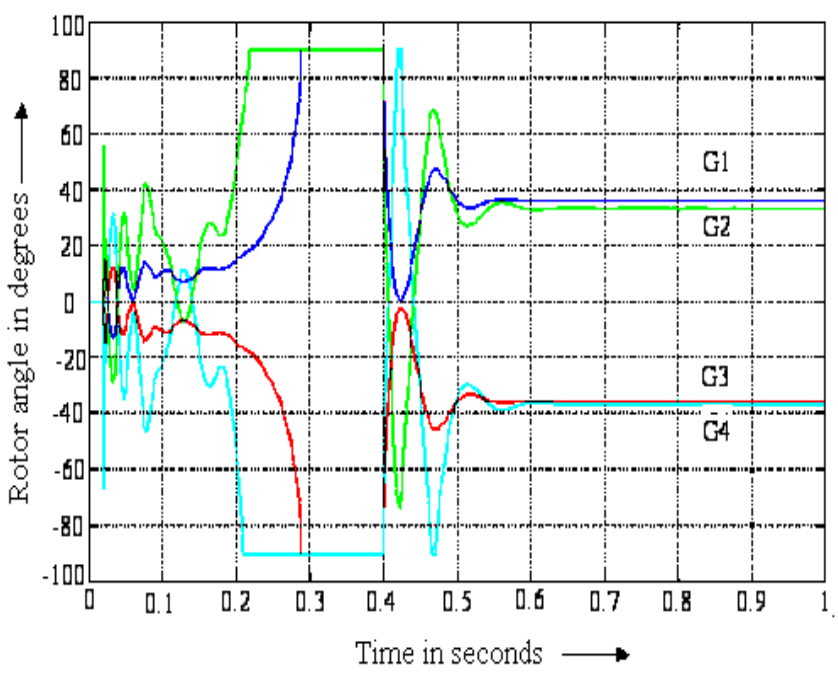

Fig. 8 Variation of generator rotor angle of the two-area power system with UPFC

\subsection{Two-area Power System with SVC}

The two-area system shown in Fig. 6 is considered in this study. The system has a SVC installed at bus-2. A 3-phase symmetrical short-circuit fault of 300 milli-seconds duration occurs nearer to bus-2. The system is simulated in Matlab/Simulink environment and the variation of bus-2 voltage is given in Fig. 9. From the Fig.9, it is clear that the voltage stability of the system is improved with SVC.

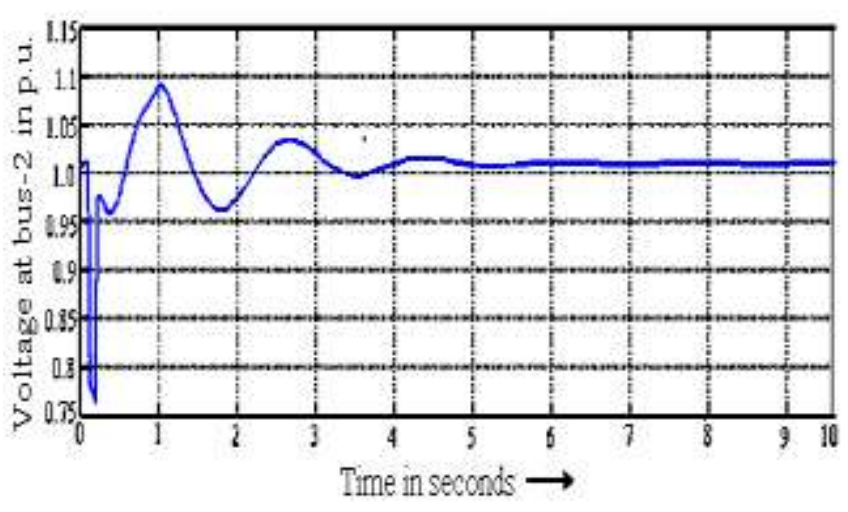

Fig. 9 Variation of bus-2 voltage of two area power system with SVC

\subsection{Two-area Power System with TCSC}

The two-area system shown in Fig. 5 is considered in this study. The system has a TCSC installed between bus-2 and bus-3. A 3phase symmetrical short-circuit fault of 300 milli-seconds duration occurs at bus-3. The system is simulated in Matlab/Simulink environment and the variation of line power transmitted is shown in Fig. 10. From the Fig. 10, it is clear that the power system stability of the system is improved with TCSC.

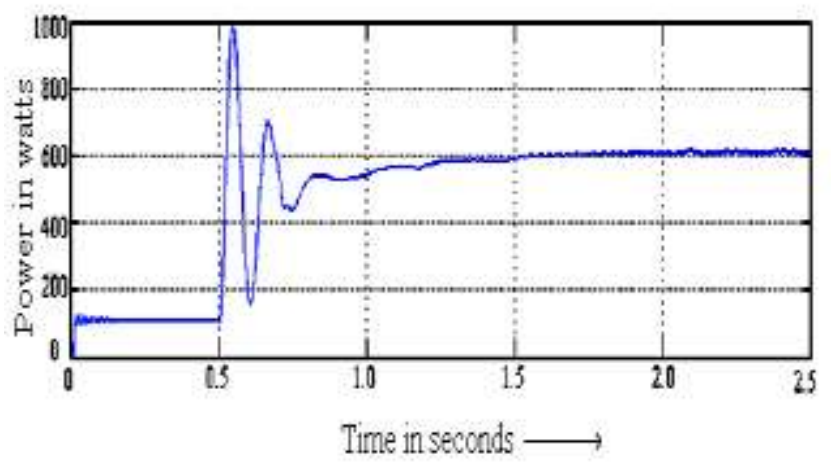

Fig. 10 Variation of line power of two-area power system with TCSC

\subsection{Two-area Power System with SSSC}

The two-area system shown in Fig. 5 is considered in this study. The system has a SSSC installed between bus-2 and bus-3. A 3phase symmetrical short-circuit fault of 300 milli-seconds duration occurs at bus-3. The system is simulated in Matlab/Simulink environment and the variation of line power transmitted is shown in Fig. 11. From the Fig. 11, it is inferred that the stability of the power system is improved with SSSC. To show the settling time for line power, the time scale starts from 6 seconds. 


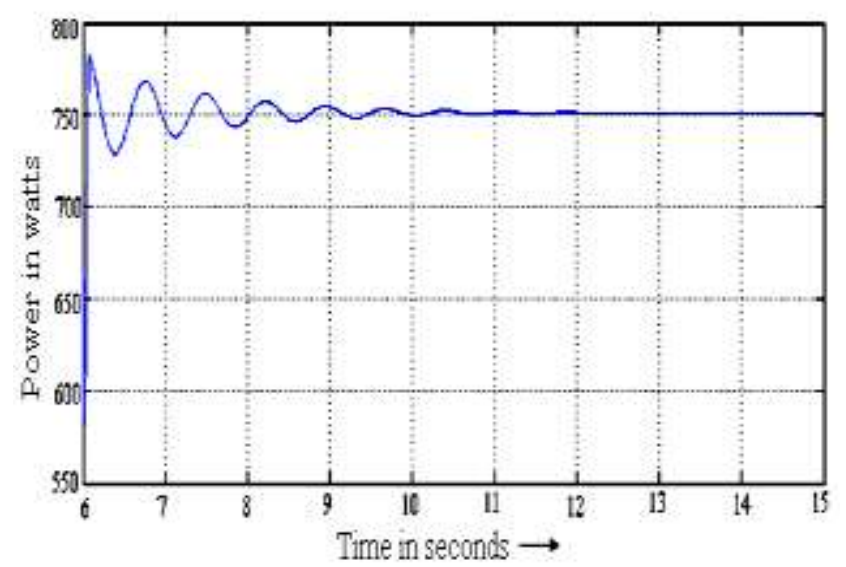

Fig. 11 Variation of line power of two-area power system with SSSC

\subsection{Comparison between UPFC, SVC, TCSC, and SSSC for Power System Stability Enhancement}

From the simulation results shown in Figs. 7 - 11, a comparison is made between the above FACTS devices for stability enhancement of two-area power system under study as shown in Table 1. From the Table 1, it is investigated that the UPFC is the effective FACTS device for stability enhancement of inter-area power system.

Table 1: Comparison between FACTS Devices for Power System Stability Enhancement

\begin{tabular}{|c|c|c|}
\hline $\begin{array}{c}\text { Two-area Power } \\
\text { System } \\
\text { with }\end{array}$ & $\begin{array}{c}\text { Power System } \\
\text { Stability } \\
\text { Enhancement }\end{array}$ & $\begin{array}{c}\text { Settling time in } \\
\text { post fault period } \\
\text { (in seconds) }\end{array}$ \\
\hline UPFC & YES & 0.6 \\
\hline TCSC & YES & 1.5 \\
\hline SVC & YES & 7 \\
\hline SSSC & YES & 11 \\
\hline
\end{tabular}

\section{CONCLUSION}

In this paper, the power system stability enhancement of a twoarea power system by various FACTS devices is presented and discussed. The dynamics of the system is compared with and without the presence of UPFC in the system in the event of a major disturbance. Then the performance of the UPFC for power system stability improvement is compared with the other FACTS devices such as SVC, TCSC, and SSSC respectively. It is clear from the simulation results that there is a considerable improvement in the system performance with the presence of UPFC for which the settling time in post fault period is found to be around 0.6 second.

\section{REFERENCES}

[1] R. Mihalic, P. Zunko and D. Povh, 1996, "Improvement of Transient Stability using Unified Power Flow Controller," IEEE Transactions on Power Delivery, 11(1), pp. 485-491.

[2] K.R. Padiyar, 2002, "Power System Dynamic Stability and Control," Second Edition, BS Publications, Hyderabad.

[3] Igor Papic, Peter Zunko, 2002, "Mathematical Model and Steady State Operational Characteristics of a Unified Power Flow Controller,"Electro-technical Review, Slovenija, 69(5), pp. 285-290.

[4] Prechanon Kumkratug, 2009, "Application of UPFC to Increase Transient Stability of Inter-Area Power System," Journal of Computers, 4(4), pp. 283-287.

[5] Prechanon Kumkratug, Panthep Laohachai, 2007, "Direct Method of Transient Stability Assessment of a Power System with a SSSC," Journal of Computers, 2(8), pp. 7782.

[6] S.V. Ravi Kumar, S. Siva Nagaraju, 2007, "Transient Stability Improvement using UPFC and SVC," ARPN Journal of Engineering and Applied Sciences, 2(3), pp. 3845.

[7] A. Kazemi, F. Mahamnia, 2008, "Improving of Transient Stability of Power Systems by Supplementary Controllers of UPFC using Different Fault Conditions," WSEAS Transactions on Power Systems, 3(7), pp. 547-556.

[8] S. Panda, Ramnarayan N. Patel, 2006, "Improving Power System Transient Stability with an off-centre Location of Shunt FACTS Devices," Journal of Electrical Engineering, 57(6), pp. 365-368.

[9] N.G. Hingorani, L. Gyugyi, 1999, "Understanding FACTS: Concepts and Technology of Flexible AC Transmission Systems," IEEE Press, New York.

[10] N. Mithulananthan, C.A. Canizares, J. Reeve, Graham J. Rogers, 2003, "Comparison of PSS, SVC and STATCOM Controllers for Damping Power System Oscillations," IEEE Transactions on Power Systems, 18(2), pp. 786-792.

[11] E.Z. Zhou, 1993, "Application of Static Var Compensators to Increase Power System damping," IEEE Transactions on Power Systems, 8(2), pp. 655-661.

[12] P. Mattavelli, G.C. Verghese, A.M. Stankovic, 1997, "Phasor Dynamics of Thyristor-Controlled Series Capacitor Systems," IEEE Transactions on Power Systems, 12(3), pp. 1259-1267.

[13] B.H. Li, Q.H. Wu, D.R. Turner, P.Y. Wang, X.X. Zhou, 2000, "Modeling of TCSC Dynamics for Control and Analysis of Power System Stability," Electrical Power \& Energy Systems, 22(1), pp. 43-49.

[14] A.D. Del Rosso, C.A. Canizares, V.M. Dona, 2003, “A Study of TCSC Controller Design for Power System Stability Improvement," IEEE Transactions on Power Systems, 18(4), pp. 1487-1496.

[15] L. Gyugyi, 1994, "Dynamic Compensation of AC Transmission Line by Solid State Synchronous Voltage 
Sources," IEEE Transactions on Power Delivery, 9(22), pp. 904-911.

[16] M. Noroozian, L. Angquist, M. Ghandhari, G. Andersson, 1997, "Use of UPFC for Optimal Power Flow Control," IEEE Transactions on Power Delivery, 12(4), pp. 16291634.

[17] M. Ghandhari, G. Andersson, I.A. Hiskens, 2001, “Control Lyapunov Functions for Series Devices," IEEE Transactions on Power Delivery, 16(4), pp. 689-694.

[18] P. Kumkratug, M.H. Haque, 2003, "Versatile Model of a Unified Power Flow Controller in Simple System," IEE Proc. Gener. Transm. \& Distrib., 150(2), pp. 155-161.
[19] V. Vittal, N. Bhatia, A.A. Fouad, 1991, "Analysis of the Inter-area Mode Phenomenon in Power Systems Following Large Disturbances," IEEE Transactions on Power Systems, 6(4), pp. 1515-1521.

[20] R.M. Mathur, R.K. Varma, 2002, "Thyristor-based FACTS Controllers for Electrical Transmission Systems," IEEE Press, Piscataway.

[21] P. Kundur, 1994, "Power System Stability and Control," McGraw-Hill, New York. 